IMPLICATIONS FOR PRACTITIONERS

\section{Managing people and learning - major challenge for modern managers}

\author{
Nataša Rupčić \\ Faculty of Economics, University of Rijeka, Rijeka, Croatia
}

Implications

for

practitioners

Received 8 July 2016 Revised 31 January 2017 Accepted 31 January 2017

\title{
Introduction
}

This issue offers many interesting features and implications for practitioners. Simonin tested N-loop learning in international strategic alliances, Poell and Van Der Kroght focused on HRD, Hillon and Boje discussed dialectics in the context of higher education, Sasaki emphasized the importance of systems intelligence (SI) in knowledge management (KM), and Göktürk et al. investigated error management practices in two state university departments.

In Part II of their paper, Poell and Van Der Krogt (2017) continue to examine human resource management and development. Employee training, education and development are often considered one of the most effective ways to stimulate and manage organizational change. However, many managers agree that HRM process is very difficult in practice, often yielding dubious results. In this regard, the authors present a conceptual framework in which they identify limited and one-sided conceptualization of organizing HRM as one of the main reasons why HRM still produces poor results. The authors suggest a learningnetwork perspective as a broader approach to organizing HRM. Employees are the key factor in this perspective, acting as important stakeholders in designing strategic HRM activities.

Practitioners should keep in mind that HRM should not be limited to training, which is related to the direct work of employees. For better results, a more comprehensive approach is advisable. Employees can and should learn from their primary work processes, both routine and project-based, which can help them gain a diversity of knowledge and experience. However, employees should also take part in programs focusing on the development of their careers. Career management benefits individuals by developing their talents through challenging and interesting tasks, increases their motivation, provides more favorable labor contracts and improves their employability. Somewhere in the middle lies the third HRM path - explicitly organized human resource development (HRD). Besides taking courses and attending seminars and conferences, employees should be stimulated to interact with other individuals and groups (colleagues, experts, etc.) as well as engage in a self-study and reflect on their own performance.

Managers should keep in mind that their role in all HRM and HRD activities is crucial. Not only are they responsible for providing organizational infrastructure but their role is also pivotal in yet another respect: they should help employees gain a better understanding on how those activities can contribute to their development. Ideas

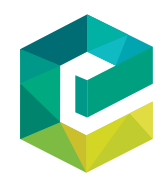

The Learning Organization Vol. 24 No. 4, 2017 pp. $257-261$ pp. $257-261$ DOI 10.1108/TLO-02-2017-0014 
TLO

24,4

258

important for practitioners based on the work by Poell and Van Der Krogt are summarized and conceptualized in Table I. However, readers are encouraged to explore further a comprehensive elaboration of ideas relevant to HRM and HRD presented in the paper.

After discussing and integrating views regarding different hierarchical levels of learning in Part I, in Part II of his paper, Simonin (2017) proposed and tested a model capturing single- and double-loop learning and their influence on collaborative knowhow in international strategic alliances. Inter-organizational collaborations are formed for a multitude of reasons, which can be summarized in three somewhat overlapping groups: minimization of production and transaction costs; profit maximization through joint strategic approach; and knowledge acquisition and transfer. As international enterprises operate in different and changing environments, capability to adapt quickly is key to their success and survival. However, adaptability is highly learningdependent. That is why it has become interesting to examine international enterprises as learning organizations and study their ability to engage in organizational learning and $\mathrm{KM}$

Practitioners in any organization as well as those engaged in various forms of interorganizational collaborations should put special emphasis on single- and double-loop organizational learning. When engaging in single-loop learning, organizations learn incrementally by detecting variations from established goals, norms and routines and introducing corrective measures. In inter-organizational collaborations, single-loop learning can refer to incremental adjustments in different collaborative activities, such as joint R\&D. On the other hand, double-loop organizational learning results in major departures from existing routines as a response to challenging situations. New solutions, such as structural and functional changes, are often a product of experimentation and can result in new forms or modes of collaboration and a higher-order collaborative know-how.

Simonin proved in his research using a large sample of technology firms that double-loop learning significantly and positively affects the development of collaborative know-how. Companies excelling in double-loop learning can therefore tap into a greater variety of opportunities and implement different modes of collaboration, which can subsequently create new learning opportunities and stimulate collaborators to develop new organizational routines to better match environmental conditions. On the other hand, while excellence in single-loop learning can be beneficial in a certain period, it can cause companies to become

\begin{tabular}{|c|c|c|c|}
\hline What & Work-related learning & $\begin{array}{l}\text { HRM as a learning network } \\
\text { Organized HRD processes }\end{array}$ & Career development \\
\hline Who & Employees & $\begin{array}{l}\text { Employee initiatives Managerial } \\
\text { engagement }\end{array}$ & $\begin{array}{l}\text { Combination of individual } \\
\text { and organizational needs } \\
\text { and preferences }\end{array}$ \\
\hline How & $\begin{array}{l}\text { Predominantly thematizing } \\
\text { (determining a work-related } \\
\text { learning path, setting } \\
\text { learning goals, problem- } \\
\text { solving, experimentation) }\end{array}$ & $\begin{array}{l}\text { Predominantly explicitly } \\
\text { operating strategically (learning } \\
\text { driven by individual values, } \\
\text { norms, and insight; network of } \\
\text { internal and external colleagues } \\
\text { and experts) }\end{array}$ & $\begin{array}{l}\text { Predominantly } \\
\text { problematizing (emphasis } \\
\text { placed on developing } \\
\text { career prospects, and/or } \\
\text { gaining other types of } \\
\text { knowledge and experience) }\end{array}$ \\
\hline $\begin{array}{l}\text { Underlying } \\
\text { motivation }\end{array}$ & \multicolumn{3}{|c|}{$\begin{array}{c}\text { Development of meaning and purposefulness in employee-colleague-expert-management } \\
\text { interactions and negotiations }\end{array}$} \\
\hline
\end{tabular}

Table I.

HRM as a learning network
Underlying 
stuck in the so-called "competency traps", when implemented routines become irrelevant or even counter-productive.

Practitioners should keep in mind that the two forms of organizational learning - singleand double-loop learning - represent two extremes on the organizational learning continuum, with a wide range of nuanced behavior between them. That is why it is beneficial that managers examine the propensity or likelihood of the described behavior in their organizations as well as in inter-organizational collaborations, as both have merits. Readers are also encouraged to further explore both types of organizational learning as well as possible collaborative forms (structural arrangements) and collaborative modes (functional arrangements), as described by Simonin.

Hillon and Boje (2017) further elaborate on modalities of practice by introducing dialectic reasoning and implementing it in the context of higher education. This article is therefore especially interesting for practitioners in higher education, particularly deans and administrators facing various challenges. Introduction of dialectics is also very interesting for academics and practitioners developing learning organizations. Organizations develop and evolve through individual and group interactions characterized by debate and rhetoric. While debate is aimed at persuading the other party of the validity of one's arguments and does not make way for compromise or collaborative solutions, the intent behind using rhetoric is to inform and motivate the audience, which makes it a milder form of persuasion.

While both techniques are useful and important in organizational life, dialectics is more akin to the learning organization philosophy. Dialectics is a process in which involved parties also try to discover the truth about something. However, opposing arguments are not considered mutually exclusive, and their integration is welcome. According to the more advanced quantum perspective, oppositions and synthesis are transcended towards a state of current incompleteness or, in other words, the realization of reality that is ever evolving. This view is consistent with modern organizational practice that is under the influence of a variety of internal and external factors, which are interrelated and interacting with one another through various mediators. Practitioners wishing to develop and sustain a learning organization should nourish dialectics as a learning process leading to change that could match environmental complexity. Storytelling is one of the tools to accomplish that goal.

Higher education organizations have the potential to cultivate learning organization ideas. However, higher education has become a highly competitive business facing many challenges, especially resource scarcity, which has led to the so-called "academic capitalism". Instead of inducing a collective dialogue and action among stakeholders based on the implementation of dialectics, many higher education institutions have decided to implement business process reengineering, despite evidence of its detrimental effects in business. The introduction of consultants and the top-down approach, while excluding engagement of other stakeholders, led to equally miserable outcomes in colleges. The main argument for such actions was the TINA ("There is No Alternative") narrative. Higher education practitioners are encouraged to review case studies presented by Hillon and Boje (2017) to avoid similar pitfalls in their institutions.

Göktürk et al. (2017) also discuss higher education environment with the purpose to identify error management practices. In their study, the authors identified three factors that influenced error management practices: organization structure; features of the national and organizational culture; and technology. Findings of their study are especially useful for
Implications for practitioners 
practitioners in the collectivist societies. Problem areas and guidelines for effective error management are presented in Table II.

One of the most challenging aspects of implementing learning organizations is reaching the stage where organizational members implement the discipline of systems thinking. Systems thinking is also very important in KM. Practitioners engaged in KM have probably already realized that implemented KM IT systems do not significantly help grasp the full potential or organizational knowledge. Knowledge is essentially created, shared and implemented in social interactions. SECI model is one of the best known in this regard, consisting of phases such as socialization, externalization, combination and internalization of knowledge. To introduce systems thinking to the SECI model, Sasaki (2017) examined SI, a kind of human intelligence based on systems thinking. Individuals should be encouraged to act as intelligent agents and perceive themselves as a part of the whole, study the influence of the whole upon themselves and examine their possible influence on the system as a whole. Some examples of intelligent human behavior implemented in the SECI model are presented in Table III.

Table II.

Problem areas and guidelines for effective error management in the educational environment in the collectivist society

\begin{tabular}{|c|c|c|c|}
\hline \multirow{2}{*}{$\begin{array}{l}\text { Processes } \\
\text { Error } \\
\text { detection }\end{array}$} & \multicolumn{3}{|c|}{ Error management as a learning process } \\
\hline & $\begin{array}{l}\text { Modes: } \\
\text { Self-realization; } \\
\text { Witnessing; } \\
\text { Information in social } \\
\text { settings }\end{array}$ & $\begin{array}{l}\text { Proceeding: } \\
\text { Self-realization: self-correction; } \\
\text { Small errors by others: none; } \\
\text { Major errors by others: } \\
\text { reported to management }\end{array}$ & $\begin{array}{l}\text { Underlying problems: } \\
\text { Conflict avoidance; } \\
\text { Avoidance of collective; punitive } \\
\text { actions }\end{array}$ \\
\hline $\begin{array}{l}\text { Error } \\
\text { management }\end{array}$ & $\begin{array}{l}\text { Proceeding by } \\
\text { management: } \\
\text { Punishment to all }\end{array}$ & $\begin{array}{l}\text { Implications: } \\
\text { Frustration stress }\end{array}$ & $\begin{array}{l}\text { Suggestions for practitioners: } \\
\text { Individual responsibility/ } \\
\text { enforcement; } \\
\text { Flexible organizational structure to } \\
\text { stimulate coordination and } \\
\text { accountability }\end{array}$ \\
\hline $\begin{array}{l}\text { Error } \\
\text { prevention }\end{array}$ & $\begin{array}{l}\text { Reality: } \\
\text { Attempts lacking or } \\
\text { limited; } \\
\text { Delayed response }\end{array}$ & $\begin{array}{l}\text { Implications: } \\
\text { Crisis; } \\
\text { Stress }\end{array}$ & $\begin{array}{l}\text { Suggestions for practitioners: } \\
\text { Organizational restructuring; } \\
\text { Scheduled meetings; } \\
\text { IT solutions }\end{array}$ \\
\hline
\end{tabular}

\begin{tabular}{ll}
$\begin{array}{l}\text { Components of the } \\
\text { SECI model }\end{array}$ & Examples of individual system intelligence behavior \\
\hline Socialization & $\begin{array}{l}\text { Managers: walk around and observe, start conversations with employees to } \\
\text { determine their opinion and feelings, share tacit knowledge with them } \\
\text { Employees: look for new opportunities to interact with customers and colleagues, } \\
\text { look for new ways to gain and share knowledge } \\
\text { Managers and employees: willingly externalize tacit knowledge with stakeholders, } \\
\text { stimulate them to express their tacit knowledge, feelings, insight, etc. } \\
\text { Managers and employees: use IT systems even when other shun them and } \\
\text { Externalization }\end{array}$ \\
Combination & $\begin{array}{l}\text { Managers and employees: nourish the belief that new individually gained tacit } \\
\text { knowledge has potential in practical usage and further socialization }\end{array}$
\end{tabular}

Components of the SECI model Examples of individual system intelligence behavior

Table III.

SI in SECI model Source: Based on Sasaki (2017) 
We should once again conclude that raising individual and collective awareness is more important than introducing new tools, techniques or technologies. Considering the fact that SI is inherent to every individual, benefits of its wider implementation and nourishment could be exceptional.

\section{References}

Göktürk, S.., Bozoğlu, O. and Günçavdı, G. (2017), "Error management practices interacting with national and organizational culture: the case of two state university departments in Turkey", The Learning Organization, Vol. 24 No. 4, pp. 245-256.

Hillon, Y.C. and Boje, D.M. (2017), "The dialectical development of 'storytelling' learning organizations: a case study of a public research university", The Learning Organization, Vol. 24 No. 4, pp. 226-235.

Poell, R. and Van Der Kroght, F. (2017), "Why is organizing human resource development so problematic? Perspectives from the learning-network theory (Part II)", The Learning Organization, Vol. 24 No. 4, pp. 215-225.

Sasaki, Y. (2017), "A note on systems intelligence in knowledge management", The Learning Organization, Vol. 24 No. 4, pp. 236-244.

Simonin, B. (2017), "N-Loop learning: part II - an empirical investigation", The Learning Organization, Vol. 24 No. 4, pp. 202-214..

\section{Corresponding author}

Nataša Rupčić can be contacted at: natasa.rupcic@efri.hr

Implications for practitioners

\section{-}

